\title{
SIW Circular Cavity Single Mode Filter with Triangle Probe
}

\author{
Siti Aminah Nordin, Mohd Khairul Mohd Salleh, Zuhani Ismail Khan, Norfishah Ab Wahab, \\ Latifah Noh, Zakiah Mohd Yusoff \\ Faculty of Electrical Engineering, Universiti Teknologi MARA Johor, Pasir Gudang Campus, \\ 81750 Masai, Johor, Malaysia
}

\begin{tabular}{l} 
Article Info \\
\hline Article history: \\
Received Feb 1, 2018 \\
Revised Apr 21, 2018 \\
Accepted Apr 27, 2018 \\
\hline
\end{tabular}

Keywords:

Cavity resonator

Circular cavity

Surface integrated waveguide

\begin{abstract}
A novel substrate integrated waveguide (SIW) circular cavity using triangle probe are proposed in this paper. Prior to this research work, circular cavity resonator was used to achieve a miniaturization for the overall circuit size. The proposed filter provides single resonant mode, TE110. The resonant frequency of TE110 can be adjusted by varying the length and width of the SIW cavity. The proposed filter are designed to operate at frequency 3.75 $\mathrm{GHz}$ and implemented on Rogers 3210 substrate with thickness of $0.64 \mathrm{~mm}$. The insertion loss in operating band is less than $0.6 \mathrm{~dB}$ and the return loss is better than $24 \mathrm{~dB}$. Simulated result obtained using Ansoft HFSS software.
\end{abstract}

\section{Corresponding Author:}

Siti Aminah Nordin,

Faculty of Electrical Engineering, Universiti Teknologi MARA Johor, Pasir Gudang Campus, 81750 Masai, Johor, Malaysia.

Email: sitiaminah.nordin@gmail.com

\section{INTRODUCTION}

The current demand and applications on the electrical and electronics industry, signifies the evolution of the cyber-physical-system concept, where all electronic devices are intended to be able to interacted with their physical input and output instead of treated as a standalone devices. Hence, mobile and wireless communication became the targeted application which enables the miniaturization of devices with high performance electronic components [1]. The solution of using planar technology is approaching its limit which leads to a new approach of integration between waveguides and cavities [2-4].

Efforts to integrate planar technology and waveguide or cavity approach can be seen in the Substrate Integrated Waveguide (SIW) technique, where a number of plated vias are placed across the surface of the device board to assimilate the presence of the wall of waveguides and resonant cavities [5-8]. Waveguides with via-walls become the transition sections between the planar lines and a group of cavities that are arranged in a horizontal topology over the planar surface of the circuit [9].

The SIW cavities also offer a significantly enhanced performance compared to other previous available planar resonators such as high quality factors, low loss, high power capacity and ease of integration with other planar circuit [10-13]. SIW is an integrated waveguide which can be fabricated using two periodic rows of vias on a dielectric substrate. This technology makes it possible to fabricate a complete circuit in planar form. Besides, losses can be reduced by mounted on chip-sets using same substrate [14-16].

A numbers of techniques has been used to excite electromagnetic wave into cavity such as aperture slot coupler, patch and the use of probe coupler. Some of the methods were used in the antenna design [17-20]. In this paper, a triangle probe has been inserted in the SIW circular cavity filter. The concept of vertically coupled cavities topology is proposed in order to achieve circuit miniaturization, low loss and ease of wave excitation. 
The resonant cavities can be arranged vertically, in order to reduce the horizontal surface of the circuit. Thus, to achieve the above targets, a circular cavity, which is based on two-layer substrates, has been proposed with triangle probe are attached with the feed lines at input and output port in order to excite the $\mathrm{TE}_{110}$-mode wave. The length and width of the triangle probe are varied to allow on its observation effect on the resonant frequency, return loss and insertion loss, respectively. The proposed filter was design to resonate at $3.75 \mathrm{GHz}$ with high selectivity and low losses.

\section{FILTER DESIGN AND ANALYSIS}

\subsection{Circular Cavity Single Mode Principle}

The design topology starts with the equation relating the frequency resonant to the dimension of the circular cavity for a chosen mode. Where it can be calculated using general formula [21];

$$
\mathrm{f}_{\mathrm{r}}=\frac{1}{2 \pi \sqrt{\mu_{\mathrm{r}} \varepsilon_{\mathrm{r}}}} \sqrt{\left(\frac{\mathrm{x}^{\prime} \mathrm{mn}}{\mathrm{r}}\right)^{2}+\left(\frac{\mathrm{p} \pi}{\Delta \mathrm{h}}\right)^{2}} \quad T E_{m n p}
$$

where:

$$
\begin{array}{ll}
\mu_{\mathrm{r}} & : \text { permeability of the dielectric filling the cavity } \\
\varepsilon_{\mathrm{r}} & : \text { permittivity of the filling material } \\
\mathrm{r} & : \text { radius } \\
\mathrm{x}^{\prime}{ }_{\mathrm{mn}} & : \text { the mth root of Bessel function derivative of nth order } \\
\mathrm{p} & : 1,2,3 \ldots \\
\mathrm{f}_{\mathrm{r}} & : \text { resonant frequency of } T E_{m n p} \text {-mode }
\end{array}
$$

In single mode circular cavity, $\mathrm{TE}_{110}$-mode is chosen as the working mode where the values of $\mathrm{x}^{\prime}{ }_{\mathrm{mn}}$ is set based on the nth roots of nth Bessel function, $\varepsilon_{\mathrm{r}}$ and $\mu_{\mathrm{r}}$ are automatically to $8.854 \mathrm{x} 10^{-12} \mathrm{~F} / \mathrm{m}$ and $4 \pi \mathrm{x}$ $10^{-7}$ respectively. The resonant frequency $\mathrm{f}_{\mathrm{r}}$ is fixing at $3.75 \mathrm{GHz}$ where the value of $r$ can be calculated according to the formula (2).

$$
\begin{aligned}
& \mathrm{f}_{\mathrm{r}}=\frac{0.159}{\sqrt{\mu_{\mathrm{r}} \varepsilon_{\mathrm{r}}}}\left(\frac{1.8412}{\mathrm{r}}\right) \\
& \mathrm{r}=\frac{0.2928}{\mathrm{f}_{\mathrm{r}} \sqrt{\mu_{\mathrm{r}} \varepsilon_{\mathrm{r}}}}
\end{aligned}
$$

Based on the formula (3), the optimal value of $r$ is found to be $25 \mathrm{~mm}$. Besides, copper is chosen for the best conductivity in order to reduce conductor loss in the cavity.

\subsection{Circular Cavity Single Mode Structure}

The configuration of the SIW circular cavity single mode with triangle probe is shown in Figure 1. There are three layers in the structure where the second layer is used for input and output port. The triangle probes are inserted into the cavity at both sides along the circumferential surface of the waveguide and also attached with the feed lines at input and output port.

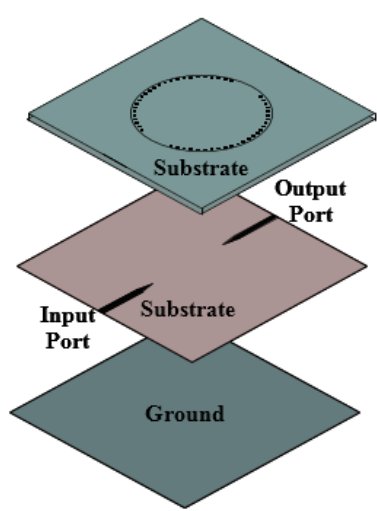

Figure 1. Configuration of SIW Circular Cavity Single Mode Filter with Triangle Probe 
The triangle probe is designed in order to excite the fields within the cavity waveguide and to maximize the energy transfer so that its field pattern is matches with the configuration of the desired mode.

The simulations are carried out to investigate the performance produce by the topology. Figure 2 shows the circular single cavity triangle probe filter structure from the top view and Table 1 indicates the parameter of the cavity structure. As shown in Figure 3, the proposed filter has center frequency at $3.75 \mathrm{GHz}$ with lower insertion loss $0.54 \mathrm{~dB}$. The maximum return loss is $24.2 \mathrm{~dB}$ over the passband.

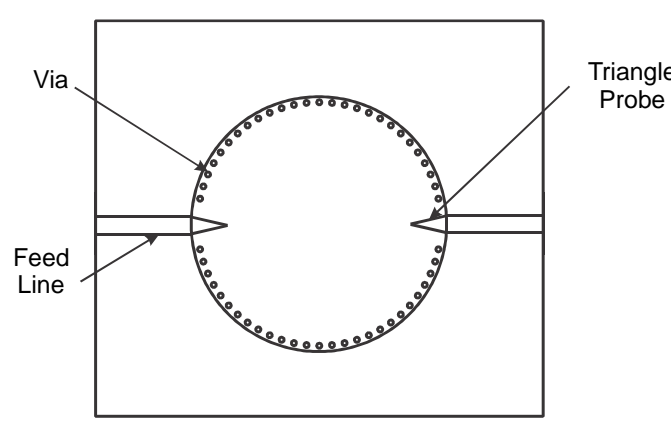

Figure 2. Top View of Circular Cavity Single Mode Filter with Triangle Probe

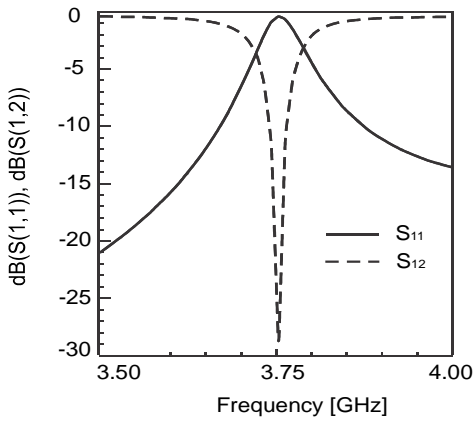

Figure 3. Simulation Result of the Proposed Filter

Table 1.Design Parameter of the Filter

\begin{tabular}{cc}
\hline Parameter & Value $(\mathrm{mm})$ \\
\hline Cavity radius & 25 \\
Via radius & 0.50 \\
width & 2.5 \\
length & 7 \\
\hline
\end{tabular}

\section{SIMULATION RESULT}

In the design, there are two controlling parameters involved in this topology which controls the frequency response of the filter, which are the length and width of the probe, respectively. These are done by varying the value of two parameters which are length and width of the triangle probe while the rest of the dimensions are being kept.

The analyses of the performances are based on the center frequency resonant, insertion loss, $\mathrm{S}_{12}$ and return loss, $S_{11}$ parameters. Figure 4 (a) and (b) shows the effect of varying the value of length and width of the triangle probe, while, Table 2 and Table 3 indicates the value of controlling parameters, $S_{11}, S_{12}$ and resonant frequency, respectively.

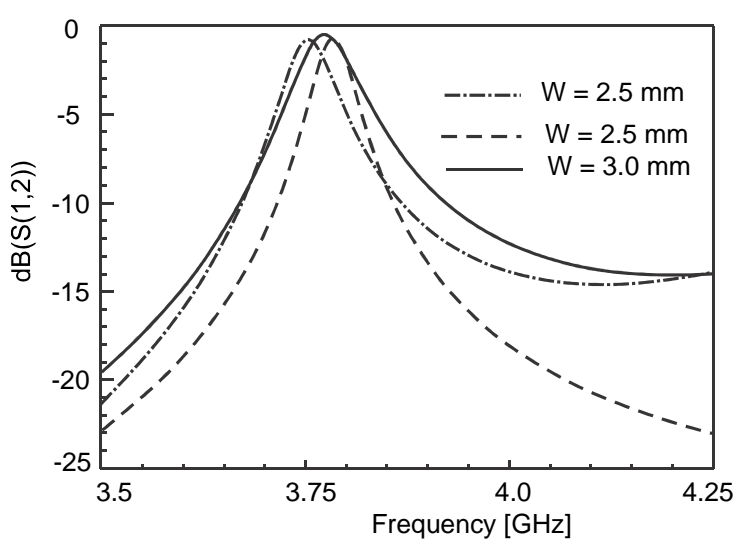

(a)

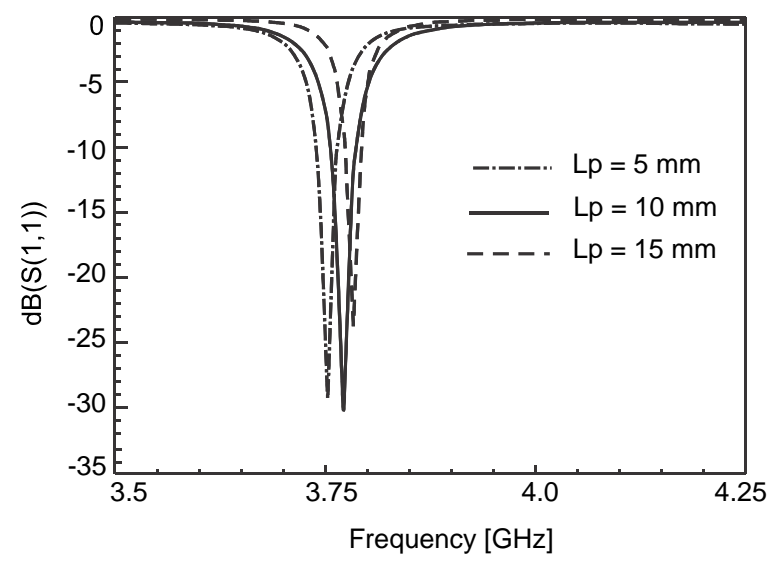

(b)

Figure 4. Effect of Varying Length and Width of the Probe 
Table 2. Variation of Probe Length with Respect to the Resonant Frequency

\begin{tabular}{ccccc}
\hline $\begin{array}{c}\text { Resonant } \\
\text { Frequency } \\
(\mathrm{GHz})\end{array}$ & $\begin{array}{c}\mathrm{Lp} \\
(\mathrm{mm})\end{array}$ & $\begin{array}{c}\mathrm{W} \\
(\mathrm{mm})\end{array}$ & $\begin{array}{c}\text { S11 } \\
(\text { Insertion } \\
\text { Loss })\end{array}$ & $\begin{array}{c}\mathrm{S} 12 \\
\text { (Return } \\
\text { Loss) }\end{array}$ \\
\hline 3.75 & 5 & 2.5 & -0.7890 & -29.599 \\
3.77 & 10 & 3.0 & -0.3466 & -30.841 \\
3.78 & 15 & 2.5 & -0.5679 & -23.656 \\
\hline
\end{tabular}

Table 3. Variation of Probe Width with Respect to the Resonant Frequency

\begin{tabular}{ccccc}
\hline $\begin{array}{c}\text { Resonant } \\
\begin{array}{c}\text { Frequency } \\
(\mathrm{GHz})\end{array}\end{array}$ & $\begin{array}{c}\mathrm{Lp} \\
(\mathrm{mm})\end{array}$ & $\begin{array}{c}\mathrm{W} \\
(\mathrm{mm})\end{array}$ & $\begin{array}{c}\text { S11 } \\
\text { (Insertion } \\
\text { Loss })\end{array}$ & $\begin{array}{c}\mathrm{S} 12 \\
\text { (Return } \\
\text { Loss) }\end{array}$ \\
\hline 3.75 & 7 & 2.5 & -0.5479 & -24.152 \\
3.76 & 7 & 3.5 & -0.4594 & -29.833 \\
3.77 & 7 & 4.5 & -0.4031 & -33.152 \\
\hline
\end{tabular}

Among the length and width of the probe studied, the best dimension ( $\mathrm{L}=10 \mathrm{~mm}$ and $\mathrm{W}=3 \mathrm{~mm}$ ) gives the closest resonant $3.77 \mathrm{GHz}$ with maximum return loss $30.8 \mathrm{~dB}$ and lowest insertion loss $0.34 \mathrm{~dB}$. Figure 5, illustrate the electric field for SIW circular single cavity filter. The substrate used for the circular single cavity filter is Rogers 3210 with relative permittivity of 10.2 and thickness of $0.64 \mathrm{~mm}$. The proposed filter will fabricated with standard PCB process.

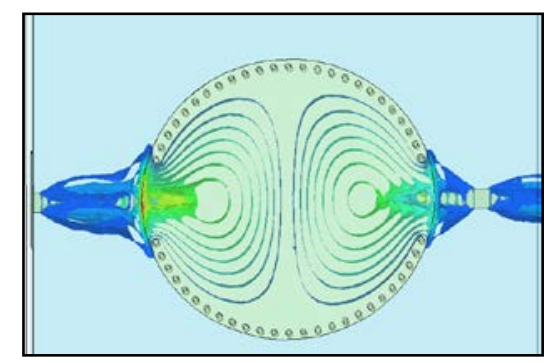

Figure 5. E-Field for SIW Cicular Single Cavity Filter

\section{CONCLUSION}

A SIW circular cavity single mode filter has been proposed to give a resonant frequency at 3.75 $\mathrm{GHz}$ for the fundamental mode $\mathrm{TE}_{110}$. Triangle probe has been inserted in the cavity to excite the wave and the simulation result shows that the resonant frequency a little shifted away from the calculated value as the length and width of the probe increased where leading to better selectivity and lower insertion loss.

\section{ACKNOWLEDGMENT}

This work was supported by the Ministry of Higher Education of Malaysia (MOHE) (Grant no: 600RMI/NRGS 5/3 (3/2013)) and the Institute of Research Management and Innovation (IRMI) of Universiti Teknologi MARA.

\section{REFERENCES}

[1] Y. Xiao Feng, Xu Yulin, Zhang Wei, Hong Ke, Wu Tie Jun, Cui, "A millimeter-wave bandpass filter and balun filter based on circular sector patch," in International Workshop on Electromagnetics: Applications and Student Innovation Competition (iWEM), 2015, pp. 1-2.

[2] Y. Zhu, J. Chen, P. Yan, "Millimeter-wave band-pass filter based on complementary split ring and SIW resonators," in Asia-Pacific Microwave Conference (APMC), 2015, pp. 1-3.

[3] H. Hu and K. L. Wu, "A TM 11 Dual-Mode Dielectric Resonator Filter With Planar Coupling Configuration," IEEE Transactions on Microwave Theory and Techniques, vol. 61, pp. 131-138, 2013.

[4] R. Beyer, P. W. Krauss, T.Sieverding, "Design of cross-coupled substrate integrated waveguide filters with the mode-matching and finite element methods," in IEEE MTT-S International Conference on Numerical Electromagnetic and Multiphysics Modeling and Optimization (NEMO), 2015, pp. 1-3.

[5] Z. Xiangjun, G. Yongxin, Wangfei , "Minimization of wideband LTCC bandpass filter using QMSIW and EMSIW cavities," in IEEE MTT-S International Microwave Workshop Series on Advanced Materials and Processes for RF and THz Applications (IMWS-AMP), 2015, pp. 1-2.

[6] J. D. Barrera and G. H. Huff, "Analysis of a Variable SIW Resonator Enabled by Dielectric Material Perturbations and Applications," IEEE Transactions on Microwave Theory and Techniques, vol. 61, pp. 225-233, 2013.

[7] M. N. Husin, H. M. T. Jusoh, M. F. M. Din, "Study and design of U-shaped patch antenna for multiband application,” Journal Fundamental Applied Sci., 2017. 
[8] C. J. You, Z. N. Chen, X. W. Zhu, K. Gong, "Single-Layered SIW Post-Loaded Electric Coupling-Enhanced Structure and Its Filter Applications," IEEE Transactions on Microwave Theory and Techniques, vol. 61, pp. 125130, 2013.

[9] S. Liu, Y. Zhang, L. Li, J. Hu, Y. Zhou, W. Zhao, R. Xu, "220GHz band-pass filter based on circular resonance cavities with low loss," in European Microwave Conference (EuMC), 2015, pp. 1077-1079.

[10] A. Hosseini-Fahraji, K. Mohammadpour-Aghdam, R. Faraji-Dana, "Design of wideband millimeter-wave bandpass filter using substrate integrated waveguide," in 24th Iranian Conference on Electrical Engineering (ICEE), 2016, pp. 772-775.

[11] K. K. A. Devi and C. H. Ng, "Analysis and Design of High Gain NRI Superstrate Based Antenna for RF Energy Harvesting System,” Indones. J. Electr. Eng.Comput. Sci., vol. 2, no. 3, 2016.

[12] L. Ma, J. Zhuang, J. Zhou, "A cross-coupled substrate integrated waveguide filter for $28 \mathrm{GHz}$ millimeter wave communications," in IEEE International Symposium on Circuits and Systems (ISCAS), 2016, pp. 814-817.

[13] A. Rahimian, "Modeling and Performance of Microwave and Millimeter-Wave Layered Waveguide Filters," Indones. J. Electr. Eng.Comput. Sci, vol. 11, no. 7, 2013, pp. 3523 - 3533.

[14] K. Dong, J. Mo, Y. He, Z. Ma, X. Yang, "Design of a millimeter-wave dual-band bandpass filter using SIW dualmode cavities," in IEEE MTT-S International Wireless Symposium (IWS), 2016, pp. 1-3.

[15] F. Huang and J. Zhou, "Quadruple-mode wideband filter using slotted substrate integrated waveguide circular cavity," in International Symposium on Antennas and Propagation (ISAP), 2016, pp. 908-909.

[16] M. N. Hafiz, M. H. Jamaluddin, and R. Selvaraju, “A Cross Slot Coupling to Enhance Bandwidth of Dual-Layer SIW Structure,”Indonesian Journal of Electrical Engineering and Computer Science, 2018, pp. 617-622.

[17] Y. Li, L. A. Yang, L. Du, K. Zhang, Y. Hao, "Design of Millimeter-Wave Resonant Cavity and Filter Using 3-D Substrate-Integrated Circular Waveguide," IEEE Microwave and Wireless Components Letters, vol. 27, pp. 706708, 2017.

[18] A. F. Abdel-Rahman and T. M. Abuelfadl, "Transient analysis of circular waveguide probe excitation using Cavity Modal Expansion," in IEEE International Symposium on Antennas and Propagation \& USNC/URSI National Radio Science Meeting, 2015, pp. 1510-1511.

[19] M. Bertrand, Z. Liu, E. Pistono, D. Kaddour, P. Ferrari, "A compact slow-wave substrate integrated waveguide cavity filter," in IEEE MTT-S International Microwave Symposium, 2015, pp. 1-3.

[20] S. Mohd Khairul Mohd, I.Zuhani, S. Mohamad Syukri, A. Zaiki, "Probe length effect on the resonant frequency of a circular cross-sectional cavity," in Electromagnetic Compatibility, 2003. EMC '03. 2003 IEEE International Symposium on, 2003, pp. 580-582 Vol.1.

[21] C. A. Balanis, Advanced Engineering Electromagnetics: Wiley, 1989. 